\title{
Self-Reported Assessment of Occupational Sitting and Physical Activity Among Employees
}

\author{
Yetty Septiani Mustar ${ }^{1, *}$ Febby Alfu Khoirun Nissa $^{2}$, Agus Hariyanto ${ }^{3,}$ \\ Bayu Agung Pramono, Indra Himawan Susanto ${ }^{5}$
}

\author{
1,2,5 Department of Health Education and Recreation, Universitas Negeri Surabaya, Surabaya, Indonesia \\ ${ }^{3,4}$ Department of Sport Coaching Education, Universitas Negeri Surabaya, Surabaya, Indonesia \\ *Corresponding author.Email:yettymustar@unesa.ac.id
}

\begin{abstract}
The high prevalence of sedentary behavior among workers is an emerging health concern due to the negative impact on human health. This study aimed to evaluate employees' sitting behavior and physical activity during their working time. A total of 130 employees participated in this study, with an average of working hours/week (38.92 \pm 20.28$)$. The crosssectional data were collected from Occupational Sitting and Physical Activity Questionnaire (OSPAQ) filled out by participants about their self-reported percentage of sitting, standing, walking, and heavy labor at work. The present data revealed that most workers reported a high rate of prolonged sitting time in the workplace, which is significantly higher among employees in the sedentary profession $(73.3 .3 \pm 9.6)$. Age and education level are also significant between physically active jobs and those with sedentary jobs. Concerning this, it is essential to develop and promote programs to reduce sedentary time and the importance of interrupting sedentary time and participating in light-intensity activities in the workplace due to the detrimental effect of sitting time on health among employees.
\end{abstract}

Keywords: Sedentary behavior, Physical activity, Worker, Workplace.

\section{INTRODUCTION}

Sedentary behavior can be defined as non-physical activities that do not require significant energy expenditure, such as sitting, lying down, watching television, reading books, and using computers [1]-[3]. Lack of physical activity (P.A.) and sedentary lifestyle has become a significant global public health problem associated with various chronic diseases, causes of death, decreased health-related quality of life, and reduced life expectancy [4]-[8].

Physical inactivity can occur due to various factors such as age, gender, health status, occupation, availability of sports facilities and equipment, and social environment [9], [10]. Currently, carrying out activities with more extended sitting portions has been considered typical at work, home, and when using transportation, even though it could be detrimental to health [11], [12]. In addition, along with the development of technology, with most of the work being screen-based with the majority of their daily time spent for prolonged sitting, sedentary behavior is increasing [13]-[17]. The research shows that office workers spend at least two-thirds of their working hours doing passive activities [18], [19]. Shift workers are also less involved in moderate-intensity physical activity and have a longer sitting time than daily workers [20]. High levels of time spent sitting with prolonged periods are associated with obesity [21]-[23], increased prevalence of cardiovascular disease, type 2 diabetes, and multiple causes of death [24]-[27].

On the other hand, since the Covid-19 outbreak and the implementation of regulations to avoid social interactions and work from home, maximizing the use of existing information and communication technology can increase sedentary behaviors and screen-based work [28], [29], which have significant health implication [30]-[32]. This is due to the restrictions in normal daily activities (such as going to the gym, parks, sports centers) can lead to changes in physical activity with possible effects on the risk of developing the chronic disease due to increased sedentary time [30], [33], [34].

Trend analysis shows that sedentary behavior will continue to increase shortly [35]. Other studies have shown that each individual spends $55-70 \%$ of their 
waking hours or the equivalent of 9-11 hours on sedentary behavior with a $2 \%$ increase for each additional hour spent [36]-[38]. In 2008, about $25 \%$ of workers in America were sedentary [13], whereas, in Australia, 47\% of women and $42 \%$ of men spent an average of 6.3 hours of their 8-hour shift in sedentary work and sitting [39]. In Thailand, the employees spend 13 hours on sedentary behavior and spend 2 hours on physical activity [40]. However, only a few documents concerning specific sitting routines and biological activities were carried out by the working population with self-reported during the COVID-19 pandemic. Therefore, it is essential to examine employees' sitting behavior and physical activity (sitting, standing, walking, and doing heavy labor) during their working time.

\section{METHODS}

\subsection{Study Design and Participants}

This is a quantitative descriptive study with a crosssectional design, conducted from June to July 2021. Participants were recruited using convenience sampling techniques from various workplaces. In this study, we included only working participants who engaged in physically active work (i.e., employees working in the health care sector, personal trainers) and workers who primarily engaged in sedentary work (i.e., office workers, manager, and administrative professions). We excluded data from non-employed respondents $(n=6)$ based on the inclusion criteria and the data cleansing process. Ultimately, a total of 130 workers aged $20-57$ years participated in this study.

\subsection{Data Collection}

The data was collected by using Occupational Sitting and Physical Activity Questionnaire (OSPAQ). It is a validated instrument to assess self-reported percentages of sitting, standing, walking, and heavy labor at work in the past seven days and the number of days worked during the past seven days [39], [41], [42]. The questionnaire also included socio-demographic data (i.e., gender, education level, body mass index, smoking habit), working conditions (i.e., work from home, work schedule, working hours, and working day). Participants have received instructions for filling out the questionnaire by describing the percentage of sitting $45 \%$, standing $25 \%$, walking $10 \%$, and doing heavy work $20 \%$ based on the rate of working time, with the result of total percentage is equal to $100 \%$.

\subsection{Statistical analysis}

We employed STATA software (Version 14) to perform statistical analysis. Descriptive data are presented in terms of percentage and mean (Standard Deviation (SD)). Differences mean between physically active and sedentary jobs were determined using an independent t-test. Chi-square was used to calculate the differences of the socio-demographic characteristic, with statistical significance set at the level of $p<0.05$.

\section{RESULTS}

The sample in this study included 130 workers (54.62\% female) aged between 20 to 30 years $(48.46 \%)$. Higher education level was obtained by $86.92 \%$ of the participants. Most body mass index was standard, working from home, daily workers, not smoking, and working as a teacher $56.92 \%, 73.85 \%, 80.77 \%, 87.69 \%$ o, and $33.85 \%$ of the participants, respectively (Table 1).

Table 1. Characteristics of socio-demographic

\begin{tabular}{|c|c|c|}
\hline \multirow{2}{*}{ Characteristic } & \multicolumn{2}{|c|}{$n=130$} \\
\hline & $\mathrm{N}$ & $\%$ \\
\hline \multicolumn{3}{|l|}{ Gender } \\
\hline Male & 59 & 45.38 \\
\hline Female & 71 & 54.62 \\
\hline \multicolumn{3}{|l|}{ Age (years) } \\
\hline $20-30$ & 63 & 48.46 \\
\hline $31-40$ & 46 & 35.38 \\
\hline$>40$ & 21 & 16.16 \\
\hline \multicolumn{3}{|l|}{ Education level } \\
\hline Medium & 17 & 13.08 \\
\hline High & 113 & 86.92 \\
\hline \multicolumn{3}{|l|}{ BMI } \\
\hline Normal & 74 & 56.92 \\
\hline Underweight & 8 & 6.15 \\
\hline Overweight & 48 & 36.92 \\
\hline \multicolumn{3}{|l|}{ WFH } \\
\hline Yes & 96 & 73.85 \\
\hline No & 34 & 26.15 \\
\hline \multicolumn{3}{|l|}{ Work Schedule } \\
\hline Day work & 105 & 80.77 \\
\hline Shift work & 25 & 19.23 \\
\hline \multicolumn{3}{|l|}{ Smokers } \\
\hline Yes & 16 & 12.31 \\
\hline No & 114 & 87.69 \\
\hline \multicolumn{3}{|l|}{ Profession } \\
\hline Personal trainer ${ }^{\mathrm{a}}$ & 9 & 6.92 \\
\hline Health care sector ${ }^{a}$ & 19 & 14.62 \\
\hline Skilled worker & 11 & 8.46 \\
\hline Lecturer $^{\mathrm{b}}$ & 8 & 6.15 \\
\hline University employee $^{\mathrm{b}}$ & 12 & 9.23 \\
\hline Administration staff $\mathrm{f}^{\mathrm{b}}$ & 21 & 16.15 \\
\hline Teacher $^{\mathrm{b}}$ & 44 & 33.85 \\
\hline Manager $^{b}$ & 6 & 4.62 \\
\hline
\end{tabular}




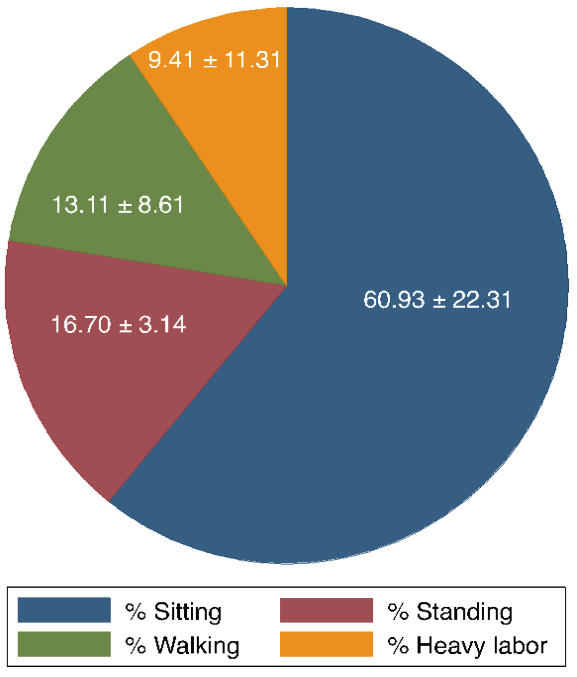

Figure 1 Self-reported percentage sitting and physical activity among employees

Participants reported that the majority of the percentage of their working time was done in a sitting position 60.93 \pm 22.31 , then standing $16.70 \pm 3.14$, walking $13.11 \pm 8.61$ and doing heavy labor $9.41 \pm 11.31$ during their working day (Figure 1).

Table 2. Working hours and working days in the last 7day during the workday

\begin{tabular}{|l|c|c|}
\hline \multirow{2}{*}{\multicolumn{1}{|c|}{ Domain }} & \multicolumn{2}{c|}{$\mathrm{n}=\mathbf{1 3 0}$} \\
\cline { 2 - 3 } & Mean & SD \\
\hline Workhours/week & 38.92 & 20.28 \\
\hline Workdays/week & 5.4 & 1.2 \\
\hline Workhours/day & 6.9 & 3.04 \\
\hline
\end{tabular}

Additionally, the average working hours/week, working day/week, along with working hours/day among employees, $38.92 \pm 20.28$ hours/week, $5.4 \pm 1.2$ day/week, and $6.9 \pm 3.04$ hours/day, respectively (Table 2).

The differences of participants between both employment types are presented in Table 3. Due to the data distribution on sitting, standing, walking, and performing heavy labor at work are not normally distributed, so we used the Wilcoxon rank-sum (MannWhitney) test to calculate the difference between employment types groups. Of the total sample, for participants with physically active jobs, the percentage of each activity, based on self-reported sitting, standing, walking, and heavy labor, was significantly different compared to the portions of participants with sedentary jobs. Furthermore, the differences based on demographic characteristics of participants between physically active jobs and those with sedentary jobs, significant differences only found in age and education level with a p-value of 0.006 and 0.005 , respectively.

Table 3. Difference between employment types

\begin{tabular}{|c|c|c|c|}
\hline & \multicolumn{3}{|c|}{$N=130$} \\
\hline & $\begin{array}{l}\text { Physically } \\
\text { active jobs } \\
\text { (n = 39) }\end{array}$ & $\begin{array}{c}\text { Sedentary } \\
\text { jobs } \\
(\mathbf{n}=91)\end{array}$ & $\begin{array}{c}\text { p- } \\
\text { value }\end{array}$ \\
\hline$\%$ Sitting & $32.3(16.3)$ & $73.3(9.6)$ & $0.000^{*}$ \\
\hline$\%$ Standing & $29.1(16.3)$ & $11.4(6.3)$ & $0.000^{*}$ \\
\hline$\%$ Walking & $20.4(11.1)$ & $10(4.64)$ & $0.000 *$ \\
\hline \% Heavy labor & $18.2(16.4)$ & $5.6(4.7)$ & $0.000^{*}$ \\
\hline Work h/week & $5.33(1.17)$ & $5.42(1.22)$ & 0.537 \\
\hline Work d/week & $37.2(16.0)$ & 39.64 (21.9) & 0.947 \\
\hline Work h/day & $6.17(2.4)$ & $7.21(3.23)$ & 0.289 \\
\hline Gender & $1.49(0.50)$ & $1.57(0.49)$ & 0.377 \\
\hline Age (years) & $1.33(0.47)$ & $1.59(0.49)$ & $0.006^{*}$ \\
\hline Education level & $1.74(0.44)$ & $1.92(0.26)$ & $0.005^{*}$ \\
\hline BMI & $1.38(0.49)$ & $1.43(0.50)$ & 0.681 \\
\hline WFH & $1.28(0.45)$ & $1.25(0.43)$ & 0.728 \\
\hline Work schedule & $1.25(0.44)$ & $1.16(0.37)$ & 0.225 \\
\hline Smokers & $1.92(0.26)$ & $1.85(0.35)$ & 0.229 \\
\hline
\end{tabular}

Data are presented as mean (SD), BMI-body mass index, WFH

- work from home, $h$-hours; $d$-days; *significant at 0.05

\section{DISCUSSION}

This study highlights employees' sitting behavior and physical activity (standing, walking, and heavy labor). Our results showed that the majority of participants in this study were employees with sedentary jobs. Their self-reported also revealed that most of their working time is engaged in a higher percentage of sitting $(60.93 \pm$ 22.31). Primarily during this COVID-19 pandemic, most of them work from home, with an average daily working time for sedentary jobs of $7.21 \pm 3.23$ hours/day. The results of this study are consistent with the other researchers who revealed that the majority of time spent by workers is sitting [43]-[45]. During the Covid-19 pandemic, employees who worked from home spent more time engaging in sedentary behavior [29].

Experiencing prolonged sitting time at work has become a common thing among employees [46]. College employees spend much time between 8.5 to 10.5 hours per day or about $55-65 \%$ of their day on sedentary behavior, both work and non-work time [47]. Likewise, daily workers in New Zealand got an average of 10334 steps at work as measured by a pedometer, while workers working on faculty and university staff only took 4442 and 4790 efforts, respectively [48].

The present study also disclosed that sitting was significantly lower among employees in the physically active job group (32.3 \pm 16.3$)$, and the physical activity (standing, walking, and heavy labor) was found significantly higher in the sedentary job groups ( $\mathrm{p}$-value 
0.000). It is in line with other studies showing that skilled workers and laborers had significantly higher physical activity than managers and professional workers [49], and employment rates with higher sitting times are found among those with higher socioeconomic positions [50], which is included in the category of a sedentary profession.

Socio-demographic characteristics in our study showed that age and education level were significantly higher in the sedentary job group. Previous research has shown that the younger generation [51] and higher-level education are associated with higher self-reported workplace sitting time [52]. Most sedentary workers have a higher prevalence of cardiovascular disease than jobs requiring workers to stand [53]. Epidemiological studies have proven that prolonged sitting at work can impact mental health [54]. A prospective analysis also showed that women who did not engage in physical activity, and a high amount of sitting time, would increase the risk of depressive symptoms in the future [55].

It is essential to identify ways to increase physical activity and reduce sedentary behavior in the work environment. Replacing the sitting position by standing or doing light activities is highly recommended. Experts also advise workers not to sit and spend 2-4 hours standing per 8-hour working day [56]. Besides, teaching physical activity in work routines can improve the health, welfare of workers, increase social interaction, work performance [57], reduce cancer risk factors [58], prevent depression [59], [60], disease, aging, and premature death [61].

\section{CONCLUSION}

Our research provides insight into workers' sociodemographics, sitting, standing, walking, and heavy labor. The findings of this study indicate that from the participant's self-reported, most employees have a prolonged workplace sitting time, which is the main contributor to sedentary behavior. There are also significant differences in age and education level in physically active and passive jobs. It is imperative to develop and promote a program to stay active for employees adapted to the work environment to reduce sedentary behavior and various health risks. Future research is expected to use the accelerometer to obtain accurate numbers regarding the amount of time (minutes or hours) used by participants to sit, stand, walk, and do strenuous activities in the workplace.

\section{REFERENCES}

[1] A. Biswas et al., "Sedentary time and its association with risk for disease incidence, mortality, and hospitalization in adults a systematic review and meta-analysis," Annals of Internal Medicine. 2015. DOI: 10.7326/M14-1651.

[2] N. Owen, G. N. Healy, C. E. Matthews, and D. W. Dunstan, "Too much sitting: The population health science of sedentary behavior," Exercise and Sport Sciences Reviews, 2010, DOI: 10.1097/JES.0b013e3181e373a2.

[3] M. S. Tremblay et al., "Sedentary Behavior Research Network (SBRN) - Terminology Consensus Project process and outcome," Int $J$ Behav Nutr Phys Act, vol. 14, no. 1, p. 75, Dec. 2017, DOI: $10.1186 / \mathrm{s} 12966-017-0525-8$.

[4] U. Ekelund et al., "Does physical activity attenuate, or even eliminate, the detrimental association of sitting time with mortality? A harmonized metaanalysis of data from more than 1 million men and women," The Lancet, 2016, DOI: 10.1016/S01406736(16)30370-1.

[5] C. J. Lavie, C. Ozemek, S. Carbone, P. T. Katzmarzyk, and S. N. Blair, "Sedentary Behavior, Exercise, and Cardiovascular Health," Circ Res, vol. 124, no. 5, pp. 799-815, Mar. 2019, DOI: 10.1161/CIRCRESAHA.118.312669.

[6] J. Meyer et al., "Changes in Physical Activity and Sedentary Behavior in Response to COVID-19 and Their Associations with Mental Health in 3052 US Adults," Int J Environ Res Public Health, vol. 17, no. 18, p. E6469, Sep. 2020, DOI: 10.3390/ijerph17186469.

[7] T. Peçanha, K. F. Goessler, H. Roschel, and B. Gualano, "Social isolation during the COVID-19 pandemic can increase physical inactivity and the global burden of cardiovascular disease," $A m \mathrm{~J}$ Physiol Heart Circ Physiol, vol. 318, no. 6, pp. H1441-H1446, Jun. 2020, DOI: 10.1152/ajpheart.00268.2020.

[8] X. Y. Wu, L. H. Han, J. H. Zhang, S. Luo, J. W. Hu, and K. Sun, "The influence of physical activity, sedentary behavior on health-related quality of life among the general population of children and adolescents: A systematic review," PLoS One, vol. 12, no. 11, p. e0187668, 2017, DOI: 10.1371/journal.pone.0187668.

[9] A. E. Bauman et al., "Correlates of physical activity: Why are some people physically active and others not?" The Lancet. 2012. DOI: 10.1016/S0140-6736(12)60735-1.

[10] G. W. Heath et al., "Evidence-based intervention in physical activity: Lessons from around the world," The Lancet. 2012. DOI: 10.1016/S01406736(12)60816-2.

[11] A. V. Patel et al., "Leisure time spent sitting concerning total mortality in a prospective cohort of 
U.S. adults," American Journal of Epidemiology, 2010, DOI: 10.1093/age/kwq155.

[12] H. P. Van Der Ploeg, T. Chey, R. J. Korda, E. Banks, and A. Bauman, "Sitting time and all-cause mortality risk in 222497 Australian adults," Archives of Internal Medicine, 2012, DOI: 10.1001/archinternmed.2011.2174.

[13] T. S. Church et al., "Trends over five decades in U.S. occupation-related physical activity and their associations with obesity," PLOS ONE, 2011, DOI: 10.1371/journal.pone.0019657.

[14] P. M. Genin et al., "Effect of Work-Related Sedentary Time on Overall Health Profile in Active vs. Inactive Office Workers," Front Public Health, vol. 6, p. 279, Oct. 2018, DOI: 10.3389/fpubh.2018.00279.

[15] N. Owen, P. B. Sparling, G. N. Healy, D. W. Dunstan, and C. E. Matthews, "Sedentary behavior: Emerging evidence for a new health risk," Mayo Clinic Proceedings. $2010 . \quad$ DOI: 10.4065/mcp.2010.0444.

[16] S. Panahi and A. Tremblay, "Sedentariness and Health: Is Sedentary Behavior More Than Just Physical Inactivity?," Front Public Health, vol. 6, p. 258, Sep. 2018, DOI: 10.3389/fpubh.2018.00258.

[17] S. Parry and L. Straker, "The contribution of office work to sedentary behavior associated risk," $B M C$ Public Health, 2013, DOI: 10.1186/1471-2458-13296.

[18] A. A. Thorp et al., "Prolonged sedentary time and physical activity in the workplace and non-work contexts: A cross-sectional study of office, customer service, and call center employees," International Journal of Behavioral Nutrition and Physical Activity, 2012, DOI: 10.1186/1479-58689-128.

[19] C. G. Ryan, P. M. Grant, P. M. Dall, and M. H. Granat, "Sitting patterns at work: objective measurement of adherence to current recommendations," Ergonomics, 2011, DOI: 10.1080/00140139.2011.570458.

[20] P. D. Loprinzi, "The effects of shift work on freeliving physical activity and sedentary behavior," Preventive Medicine, 2015, DOI: 10.1016/j.ypmed.2015.03.025.

[21] F. C. Mussi, F. J. G. Pitanga, and C. G. da S. Pires, "Cumulative sitting time as a discriminator of overweight, obesity, abdominal obesity and lipid disorders in nursing university," Rev. bras. cineantropom. desempenho hum., vol. 19, pp. 4049, Feb. 2017, doi: 10.5007/1980$0037.2017 \mathrm{v} 19 \mathrm{n} 1 \mathrm{p} 40$.
[22] M. Paz-Krumdiek, S. G. Rodriguez-Vélez, P. Mayta-Tristán, and A. Bernabe-Ortiz, "Association between sitting time and obesity: A populationbased study in Peru," Nutr Diet, vol. 77, no. 2, pp 189-195, Apr. 2020, DOI: 10.1111/17470080.12540.

[23] F. Yuan et al., "Association of Physical Activity and Sitting Time with Overweight/Obesity in Chinese Occupational Populations," OFA, vol. 14, no. 1, pp. 141-147, 2021, DOI: $10.1159 / 000512834$.

[24] D. P. Bailey, D. J. Hewson, R. B. Champion, and S. M. Sayegh, "Sitting Time and Risk of Cardiovascular Disease and Diabetes: A Systematic Review and Meta-Analysis," Am J Prev Med, vol. 57, no. 3, pp. 408-416, Sep. 2019, DOI: 10.1016/j.amepre.2019.04.015.

[25] J. Y. Chau et al., "Daily sitting time and all-cause mortality: A meta-analysis," PLoS ONE, 2013, DOI: 10.1371/journal.pone.0080000.

[26] P. C. Dempsey, N. Owen, S. J. H. Biddle, and D. W. Dunstan, "Managing sedentary behavior to reduce the risk of diabetes and cardiovascular disease," Current Diabetes Reports. 2014. DOI: 10.1007/s11892-014-0522-0.

[27] R. Patterson et al., "Sedentary behavior and risk of all-cause, cardiovascular and cancer mortality, and incident type 2 diabetes: a systematic review and dose-response meta-analysis," Eur J Epidemiol, vol. 33, no. 9, pp. 811-829, Sep. 2018, DOI: 10.1007/s10654-018-0380-1.

[28] N. Fukushima et al., "Associations of working from home with occupational, physical activity and sedentary behavior under the COVID-19 pandemic," J Occup Health, vol. 63, no. 1, p. e12212, Jan. 2021, DOI: 10.1002/13489585.12212.

[29] C. P. McDowell, M. P. Herring, J. Lansing, C. Brower, and J. D. Meyer, "Working From Home and Job Loss Due to the COVID-19 Pandemic Are Associated With Greater Time in Sedentary Behaviors," Frontiers in Public Health, 2020, DOI: 10.3389/fpubh.2020.597619.

[30] B. Barone Gibbs, C. E. Kline, K. A. Huber, J. L. Paley, and S. Perera, "Covid-19 shelter-at-home and work, lifestyle and well-being in desk workers," Occupational medicine (Oxford, England), 2021, DOI: 10.1093/occupied/kqab011.

[31] S. K. Brooks et al., "The psychological impact of quarantine and how to reduce it: a rapid review of the evidence," The Lancet. 2020. DOI: 10.1016/S0140-6736(20)30460-8.

[32] L. A. Brusaca, D. F. Barbieri, S. E. Mathiassen, A. Holtermann, and A. B. Oliveira, "Physical behaviors in Brazilian office workers working from 
home during the COVID-19 pandemic, compared to before the pandemic: A compositional data analysis," International Journal of Environmental Research and Public Health, 2021, DOI: 10.3390/ijerph18126278.

[33] G. H. Tison et al., "Worldwide Effect of COVID19 on Physical Activity: A Descriptive Study," Annals of internal medicine. 2020. DOI: 10.7326/M20-2665.

[34] E. L. Caputo and F. F. Reichert, "Studies of Physical Activity and COVID-19 during the Pandemic: A Scoping Review," Journal of Physical Activity and Health. 2020. DOI: 10.1123/jpah.2020-0406.

[35] H. W. Kohl et al., "The pandemic of physical inactivity: Global action for public health," The Lancet, vol. 380, no. 9838, pp. 294-305, 2012, DOI: $10.1016 / \mathrm{S} 0140-6736(12) 60898-8$.

[36] M. P. Jans, K. I. Proper, and V. H. Hildebrandt, "Sedentary Behavior in Dutch Workers. Differences Between Occupations and Business Sectors," American Journal of Preventive Medicine, 2007, DOI: 10.1016/j.amepre.2007.07.033.

[37] M. Kang and D. A. Rowe, "Issues and Challenges in Sedentary Behavior Measurement," Measurement in Physical Education and Exercise Science, 2015, DOI: 10.1080/1091367X.2015.1055566.

[38] J. L. Urda, J. S. Lynn, A. Gorman, and B. Larouere, "Effects of a minimal workplace intervention to reduce sedentary behaviors and improve perceived wellness in middle-aged women office workers," Journal of Physical Activity and Health, 2016, DOI: 10.1123/jpah.2015-0385.

[39] J. Y. Chau, H. P. van der Ploeg, D. Merom, T. Chey, and A. E. Bauman, "Cross-sectional associations between occupational and leisure-time sitting, physical activity and obesity in working adults," Preventive Medicine, 2012, DOI: 10.1016/j.ypmed.2011.12.020.

[40] S. Thanamee et al., "A population-based survey on physical inactivity and leisure-time physical activity among adults in Chiang Mai, Thailand, 2014," Archives of Public Health, 2017, DOI: 10.1186/s13690-017-0210-z.

[41] K. Dillon et al., "Validity of the occupational sitting and physical activity questionnaire (OSPAQ) for home-based office workers during the COVID-19 global pandemic: A secondary analysis," Applied Ergonomics, vol. 97, p. 103551, Nov. 2021, DOI: 10.1016/j.apergo.2021.103551.

[42] J. Jancey, M. Tye, S. McGann, K. Blackford, and A. H. Lee, "Application of the Occupational Sitting and Physical Activity Questionnaire (OSPAQ) to office-based workers," BMC Public Health, vol. 14, p. 762, Jul. 2014, DOI: 10.1186/1471-2458-14-762.

[43] S. K. Rosenkranz, E. L. Mailey, E. Umansky, R. R. Rosenkranz, and E. Ablah, "Workplace Sedentary Behavior and Productivity: A Cross-Sectional Study," IJERPH, vol. 17, no. 18, p. 6535, Sep. 2020, DOI: 10.3390/ijerph17186535.

[44] N. T. Hadgraft et al., "Feasibility and acceptability of reducing workplace sitting time: a qualitative study with Australian office workers," BMC Public Health, vol. 16, no. 1, p. 933, Sep. 2016, DOI: 10.1186/s12889-016-3611-y.

[45] R. S. Mayne, N. D. Hart, and N. Heron, "Sedentary behavior among general practitioners: a systematic review," BMC Fam Pract, vol. 22, no. 1, p. 6, Jan. 2021, DOI: 10.1186/s12875-020-01359-8.

[46] G. Healy et al., "Reducing prolonged sitting in the workplace: An evidence review: full report," 2012.

[47] S. Headley et al., "Subjective and objective assessment of sedentary behavior among college employees," BMC Public Health, 2018, DOI: 10.1186/s12889-018-5630-3.

[48] G. Schofield, H. Badlands, and M. Oliver, "Objectively-measured physical activity in New Zealand workers," Journal of Science and Medicine in Sport, 2005, DOI: 10.1016/S14402440(05)80005-2.

[49] R. Steele and K. Mummery, "Occupational, physical activity across occupational categories," Journal of Science and Medicine in Sport, 2003, DOI: 10.1016/S1440-2440(03)80266-9.

[50] M. J. Duncan, M. Rashid, C. Vandelanotte, N. Cutumisu, and R. C. Plotnikoff, "Development and reliability testing of a self-report instrument to measure the office layout as a correlate of occupational sitting," International Journal of Behavioral Nutrition and Physical Activity, 2013, DOI: 10.1186/1479-5868-10-16.

[51] J. A. Bennie et al., "Total and domain-specific sitting time among employees in desk-based work settings in Australia," Australian and New Zealand Journal of Public Health, vol. 39, no. 3, pp. 237242, 2015, DOI: 10.1111/1753-6405.12293.

[52] B. Wallmann-Sperlich, J. Bucksch, S. Schneider, and I. Froboese, "Socio-demographic, behavioral and cognitive correlates of work-related sitting time in German men and women," BMC Public Health, vol. 14, no. 1, p. 1259, Dec. 2014, DOI: 10.1186/1471-2458-14-1259.

[53] D. W. Dunstan, B. Howard, G. N. Healy, and N. Owen, "Too much sitting - A health hazard," Diabetes Research and Clinical Practice. 2012. DOI: 10.1016/j.diabres.2012.05.020. 
[54] M. Kilpatrick, K. Sanderson, L. Blizzard, B. Teale, and A. Venn, "Cross-sectional associations between sitting at work and psychological distress: Reducing

[55] A. Sanchez-Villegas, I. Ara, F. Guillén-Grima, M. Bes-Rastrollo, J. J. Varo-Cenarruzabeitia, and M. A. Martinez-González, "Physical activity, sedentary index, and mental disorders in the sun cohort study," Medicine and Science in Sports and Exercise, 2008, DOI: 10.1249/MSS.0b013e31816348b9.

[56] J. P. Buckley et al., "The sedentary office: An expert statement on the growing case for change towards better health and productivity," British Journal of Sports Medicine, 2015, DOI: 10.1136/by sports-2015-094618.

[57] A. Stephenson, S. M. McDonough, M. H. Murphy, C. D. Nugent, and J. L. Mair, "Using computer, mobile and wearable technology-enhanced interventions to reduce sedentary behavior: a systematic review and meta-analysis," The international journal of behavioral nutrition and physical activity, 2017, DOI: 10.1186/s12966-0170561-4. sitting time may benefit mental health," Mental Health and Physical Activity, 2013, DOI: 10.1016/j.mhpa.2013.06.004.

[58] S. C. Moore et al., "Association of leisure-time physical activity with risk of 26 types of cancer in 1.44 million adults," JAMA Internal Medicine, 2016, DOI: 10.1001/jamainternmed.2016.1548.

[59] S. Hu, L. Tucker, C. Wu, and L. Yang, "Beneficial Effects of Exercise on Depression and Anxiety During the Covid-19 Pandemic: A Narrative Review," Frontiers in Psychiatry, vol. 11, p. 1217, 2020, DOI: $10.3389 /$ fpsyt.2020.587557.

[60] S. B. Harvey, S. Øverland, S. L. Hatch, S. Wessely, A. Mykletun, and M. Hotopf, "Exercise and the Prevention of Depression: Results of the HUNT Cohort Study," AJP, vol. 175, no. 1, pp. 28-36, Jan. 2018, doi: 10.1176/appi.ajp.2017.16111223.

[61] C. Bouchard, S. N. Blair, and P. T. Katzmarzyk, "Less sitting, more physical activity, or higher fitness?," Mayo Clinic Proceedings. 2015. DOI: 10.1016/j.mayocp.2015.08.005. 